\title{
Inhibition of CD23-mediated lgE transcytosis suppresses the initiation and development of allergic airway inflammation
}

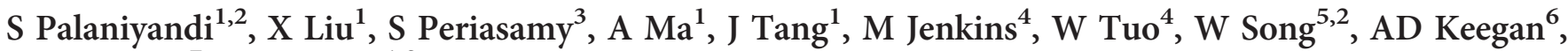 \\ $\mathrm{DH}$ Conrad $^{7}$ and $\mathrm{X} \mathrm{Zhu}^{1,2}$
}

The epithelial lining of the airway tract and allergen-specific IgE are considered essential controllers of inflammatory responses to allergens. The human low affinity IgE receptor, CD23 (Fc\&RII), is capable of transporting IgE or IgE-allergen complexes across the polarized human airway epithelial cell (AEC) monolayer in vitro. However, it remains unknown whether the CD23-dependent IgE transfer pathway in AECs initiates and facilitates allergic inflammation in vivo, and whether inhibition of this pathway attenuates allergic inflammation. To this end, we show that in wild-type (WT) mice, epithelial CD23 transcytosed both IgE and ovalbumin (OVA)-IgE complexes across the airway epithelial barrier, whereas neither type of transcytosis was observed in CD23 knockout (KO) mice. In chimeric mice, OVA sensitization and aerosol challenge of WT/WT (bone-marrow transfer from the WT to WT) or CD23KO/WT (CD23KO to WT) chimeric mice, which express CD23 on radioresistant airway structural cells (mainly epithelial cells) resulted in airway eosinophilia, including collagen deposition and a significant increase in goblet cells, and increased airway hyperreactivity. In contrast, the absence of CD23 expression on airway structural or epithelial cells, but not on hematopoietic cells, in WT/CD23KO (the WT to CD23KO) chimeric mice significantly reduced OVA-driven allergic airway inflammation. In addition, inhalation of the CD23-blocking B3B4 antibody in sensitized WT mice before or during airway challenge suppressed the salient features of asthma, including bronchial hyperreactivity. Taken together, these results identify a previously unproven mechanism in which epithelial CD23 plays a central role in the development of allergic inflammation. Further, our study suggests that functional inhibition of CD23 in the airway is a potential therapeutic approach to inhibit the development of asthma.

\section{INTRODUCTION}

Asthma, an allergic disorder that affects both adults and children, is a very heterogeneous and complex disease that involves multiple pathways and cellular components in its pathogenesis. Typically, allergic inflammation in the airway is characterized by a large increase in the numbers of immune cells such as mast cells, basophils, neutrophils, eosinophils, and innate lymphoid cells, and a skewed Th2 cytokine response with increases in interleukin (IL)-4, IL-5, and IL-13. ${ }^{1,2}$ Additionally, allergenspecific Immunoglobulin $\mathrm{E}$ (IgE) antibody is consistently present in human nasal washings and bronchoalveolar lavage (BAL) fluid and is markedly increased during human allergic rhinitis and bronchial asthma. ${ }^{3,4}$ These observations are in agreement with the fact that IgE-producing plasma cells are present in the nasal mucosa of allergic individuals, where $\mathrm{B}$ cells locally synthesize IgE, as well as in inflamed lungs. ${ }^{5,6}$ Furthermore, allergen-specific plasma cells can persist in lymphatic organs, secreting IgE over several years even in the absence of allergen. In addition, viral-specific IgE has been suggested to play a role in virus-mediated exacerbation of asthma.?

IgE antibody is essential in development of airway inflammation and airway hyper-responsiveness (AHR) because it

\footnotetext{
${ }^{1}$ Division of Immunology, Virginia-Maryland College of Veterinary Medicine, University of Maryland, College Park, MD, USA. ${ }^{2}$ Maryland Pathogen Research Institute, University of Maryland, College Park, MD, USA. ${ }^{3}$ Center for Immunology and Microbial Disease, Albany Medical College, Albany, NY, USA. ${ }^{4}$ Animal Parasitic Diseases Laboratory, Agricultural Research Service, United States Department of Agriculture, Beltsville, MD, USA. ${ }^{5}$ Department of Cell Biology and Molecular Genetics, University of Maryland, College Park, MD, USA. ${ }^{6}$ Center for Vascular and Inflammatory Diseases and Department of Microbiology and Immunology, University of Maryland School of Medicine, Baltimore, MD, USA and ${ }^{7}$ Department of Microbiology and Immunology, Virginia Commonwealth University, Richmond, VA, USA. Correspondence: XZhu (xzhu1@umd.edu).
}

Received 5 August 2014; accepted 2 February 2015; published online 18 March 2015. doi:10.1038/mi.2015.16 
links multivalent allergen binding to the high-affinity $\operatorname{IgE}$ receptor (FceRI) on the surface of sensitized mast cells and basophils, which thereby results in a cascade of enhanced cellular events and the release of potent inflammatory mediators including histamine, prostaglandins, and leukotrienes. These mediators act on epithelial cells and smooth muscle cells and are responsible for clinical symptoms in allergic diseases. ${ }^{1}$ Allergen-loaded IgE can also activate antigenpresenting cells (APCs), which subsequently prime T-cell responses. ${ }^{8}$

Unlike Fc\&RI, the role of Fc\&RII (CD23) in allergic inflammation remains elusive. $\mathrm{CD} 23$ is a type II membrane glycoprotein and its carboxyl terminus consists of a C-type lectin head that binds to IgE in a calcium-dependent manner. ${ }^{9-}$

${ }^{11}$ Although CD23 monomers display relatively low-affinity $\left(\mathrm{Ka} \approx 10^{6}-10^{7}\right)$ for IgE, the membrane-bound CD23 can form a trimer allowing $\mathrm{CD} 23$ to bind to $\operatorname{IgE}$ with high affinity $\left(\mathrm{Ka} \approx 10^{8}-10^{9}\right){ }^{9-12} \mathrm{CD} 23$ is expressed in a variety of cell types including $\mathrm{B}$ cells, activated $\mathrm{T}$ cells, eosinophils, monocytes, platelets, dendritic cells, and Langerhans cell, and possesses diverse binding partners such as integrins and CD21., ${ }^{910}$ Numerous studies have found that $\mathrm{CD} 23$ serves as a negative feedback regulator of IgE production. ${ }^{9,10,13}$ Moreover, CD23 and FceRI $\alpha$ chain bind to IgE in a mutually exclusive manner allowing IgE to function independently through these two receptors. ${ }^{14}$

The epithelial lining of airways forms a physical barrier to inhaled environmental factors such as pathogens, allergens, and pollutants through the presence of apical tight junctions that seal the paracellular space. ${ }^{15} \mathrm{~A}$ transcellular pathway known as transcytosis mediates the transport of macromolecules across the polarized airway epithelium. Our recent study has shown that CD23 constitutively expressed on human AECs is capable of transporting IgE or IgE-antigen immune complexes (ICs) across human airway epithelial monolayers by transcytosis. Moreover, the cytokine IL-4 enhances transepithelial transport of IgE and of IgE-derived ICs across AECs. ${ }^{16}$

As AECs are the first cell layer to come into contact with inhaled allergens, we postulated that when transcytosed by AECs into the airway lumen, allergen-specific IgE captures airborne allergens and form ICs, which subsequently induce potent airway inflammatory immune responses. In this and previous studies, CD23 expression is observed in airway structural cells, predominantly epithelial cells. ${ }^{16}$ Using bonemarrow chimeras generated from WT and CD23 KOs, we discovered that structural cell CD23 expression is necessary and sufficient for the initiation and perpetuation of allergic inflammatory responses in airways. Most importantly, our results demonstrate that blocking $\mathrm{CD} 23$ function in the airway should be considered as a novel therapy for allergic asthma.

\section{RESULTS}

\section{Mouse AECs express CD23}

In order to examine the function of epithelial CD23 during allergic inflammation, we characterized CD23 expression in mouse AECs. To this end, we assessed protein expression in epithelial cells isolated from WT mouse nose, lung, and trachea. Using B3B4, a rat IgG2a antibody (Ab) specific for mouse $\mathrm{CD} 23$, for detection, a $49 \mathrm{kDa}$ band was seen in each of these cell lysates as well as in lysates from splenic cells, but not $\mathrm{CHO}$ cells (Figures 1a and b). Immunohistochemical analysis of WT mouse lung confirmed CD23 expression, using the spleen as a positive control and normal rabbit IgG staining as a negative control (Figure 1c, middle panel). When cytokeratin was used as a marker for epithelial cells, colocalization of CD23 and cytokeratin indicated the expression of CD23 in lung or tracheal epithelial cells (Supplementary Figure S1 online). Similar to human $\mathrm{CD} 23$, mouse $\mathrm{CD} 23$ exists in three isoforms. ${ }^{17}$ Using RT-PCR and sequencing of PCR products for confirmation, we found that $\mathrm{CD} 23 b$, but not CD23a, mRNA was present in the mouse lung epithelial cell line LA4 (Supplementary Figure S2). In addition, exposure of LA4 cells to IL-4 resulted in enhanced expression of CD23b mRNA, but not $\mathrm{CD} 23 a$ or $\mathrm{CD} 23 \mathrm{~b} \Delta 5$ (an isoform of $\mathrm{CD} 23 b$ that lacks exon 5$)^{17}$ (Supplementary Figure S2). Thus, similar to human AECs, mouse lung epithelial cells also express CD23 $3^{16}$ indicating that epithelial cells are the major cell type highly expressing CD23 in airways.

\section{CD23 transcytoses mouse IgE across the airway epithelial barrier}

Human CD23 bidirectionally transports IgE in polarized epithelial Calu-3 cells and in primary human tracheal/ bronchial epithelial cells. ${ }^{16}$ To determine whether mouse CD23 is responsible for IgE transcytosis across AECs, we isolated primary tracheal epithelial cells from WT or CD23 KO mice. The absence of $\mathrm{CD} 23$ expression in $\mathrm{CD} 23 \mathrm{KO}$ mice was verified by both PCR and flow cytometry (Supplementary Figure S3). Cells were grown on transwell inserts $(0.4-\mu \mathrm{m}$ pore size) to form polarized monolayers. Mouse IgE was added to either the apical or the basolateral chamber, and cells were further incubated at $37^{\circ} \mathrm{C}$ for $2 \mathrm{~h}$. As a negative control, mouse AECs was also incubated with $\operatorname{IgE}$ at $4{ }^{\circ} \mathrm{C}$ for $2 \mathrm{~h}$. Assessing transcytosis of IgE by enzyme-linked immunosorbent assay (ELISA), we found that IgE applied to either the apical (Figure 2a, top panel) or the basolateral (Figure 2a, bottom panel) chamber was transported across the epithelial monolayers in the opposite direction in WT, but not CD23 KO mice. No significant IgE transcytosis was detected in epithelial monolayers incubated at $4{ }^{\circ} \mathrm{C}$, ruling out the possibility of passive diffusion. To further confirm CD23mediated IgE transcytosis across the mouse airway barrier from the apical (airway) epithelial surface to the basolateral (subepithelial and circulation) surface, we administered OVA-specific IgE (20 or $40 \mu \mathrm{g} \mathrm{ml}^{-1}$ ) or phosphate-buffered saline (PBS) intranasally (i.n.) and collected serum at 4,8 , and $24 \mathrm{~h}$ to test for the presence of OVA-specific IgE by ELISA (Figure 2b, top panel and Supplementary Figure S4A). Mouse IgE was significantly elevated in sera of the WT mice compared with CD23 KO mice (Figure $\mathbf{2 b}$, top panel) after both the 4 and $8 \mathrm{~h}$ inoculations. However, by $24 \mathrm{~h}$, the 
inoculated OVA-specific IgE was barely detectable in both WT and CD23 KO mice. To determine whether mouse IgE can also be transcytosed from the basolateral to apical surface, mouse OVA-specific IgE $\left(20\right.$ or $\left.40 \mathrm{gg} \mathrm{ml}^{-1}\right)$ or PBS was intraperitoneally (i.p.) injected and BAL fluids were collected $8 \mathrm{~h}$ later to measure IgE by ELISA (Figure $\mathbf{2 b}$, bottom panel and Supplementary Figure S4B). Similar to apical to basolateral transcytosis, a greater amount of IgE was detected in the BAL of WT mice than CD23 KO mice (Figure $\mathbf{2 b}$, bottom panel). To verify further CD23-mediated IgE transcytosis in situ, WT mice were i.n. inoculated with $\operatorname{IgE}\left(20 \mu \mathrm{g} \mathrm{ml}^{-1}\right)$ or PBS, and lung and trachea tissues were sampled for cryosectioning 20 min later. We detected IgE (green) in CD23positive (red) cells (Figure 2c), but did not find any background staining of IgE in the PBS control group. In addition to CD23positive epithelial cells, IgE (green) was also detected in the lung parenchyma underneath epithelial cells (Figure 2c), suggesting that the $\operatorname{IgE} \mathrm{Ab}$ was transported by transcytosis. Similarly, CD23-positive cells in lung tissues also showed IgE and CD23 staining, which was absent in the PBS control group.

\section{CD23 transcytoses IgE-allergen ICs across the epithelial barrier}

Our previous study showed that human $\mathrm{CD} 23$ is capable of transporting ICs across primary human tracheal/bronchial epithelial cells in vitro. ${ }^{16}$ To assess this in vivo, we first generated IgE-OVA ICs in vitro and verified them by ELISA. Mice were i.n. administered IgE-OVA ICs or OVA alone, and sera were sampled $8 \mathrm{~h}$ later to test for the presence of OVA by ELISA. As shown in Figure 3a, a higher amount of OVA, representing OVA-IgE ICs, was detected in the sera of WT, but not CD23 KO mice. Furthermore, when OVA was administered alone, it did not increase in the sera of either WT or CD23 KO mice (Figure 3a). To show transcytosis of ICs by CD23 in situ, we conducted immunohistochemical analysis that further revealed the co-localization of $\mathrm{CD} 23$ with $\mathrm{IgE}$ and OVA (Figure 3b and Supplementary Figure S5). As expected, administration of PBS did not result in any significant staining (Supplementary Figure S5, panel E). Taken together, these data clearly demonstrate CD23-dependent transport of ICs across the mouse airway epithelial barrier.

\section{CD23 in AECs promotes the development of airway allergic inflammation}

To examine the role of epithelial CD23 in allergic inflammation, we utilized an OVA-based allergy mouse model. First, $\mathrm{Balb} / \mathrm{c}$ mice were sensitized with OVA or PBS (as a negative control) followed by three challenges with OVA. Treated WT mice exhibited responses characteristic of allergic inflammation with significantly higher levels of total and OVA-specific IgE, IL-4, and a greater number of total leukocytes and eosinophils in the BAL fluid and goblet cells of the lungs compared with control mice sensitized with PBS (Supplementary Figure S6). However, in order to induce inflammation without damaging the integrity of the airway epithelium and cause leakage of the airway lining, we reduced a
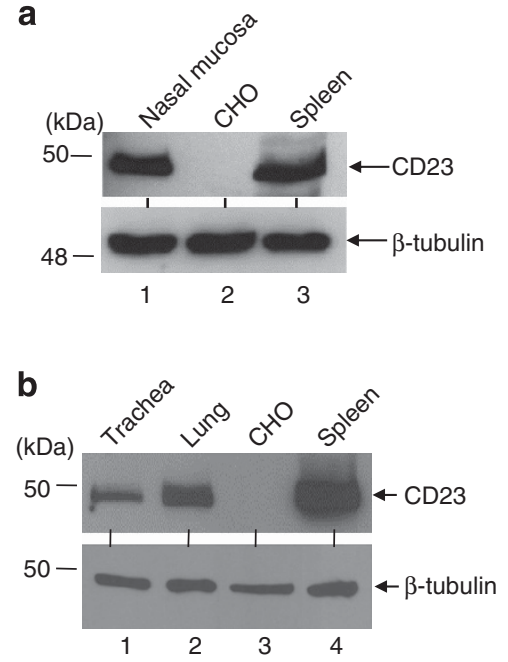

C
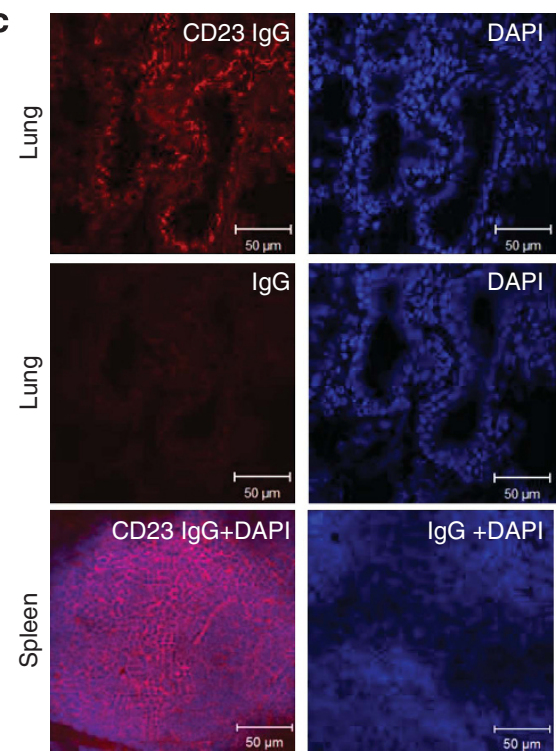

Figure 1 Expression of CD23 in mouse AECs. Cell lysates $(50 \mu \mathrm{g})$ derived from primary nasal (a), tracheal (b), and lung (b) epithelial cells were electrophoresed on a 12\% SDS-PAGE gel under reducing condition. The separated proteins were transferred onto a nitrocellulose membrane, blotted with rat anti-mouse CD23 mAb (B3B4) followed by HRP-conjugated rabbit anti-rat IgG Ab. Proteins were visualized using the ECL method. Lysates $(50 \mu \mathrm{g})$ from mouse spleen or $\mathrm{CHO}$ cells were used as a positive or negative control, respectively. $\beta$-Tubulin was used as an internal control. Arrows indicate mouse CD23 and $\beta$-tubulin. (c) Immunohistochemical staining of mouse lung. Normal mouse lung was prepared in OCT medium and cryosectioned at $5 \mu \mathrm{m}$. Frozen tissue sections were fixed and permeabilized with ice-cold acetone and blocked with 10\% normal goat serum. A spleen section was used as a positive control. Sections were incubated with rabbit anti-CD23 Ab or normal rabbit IgG, followed by staining with Alexa Fluor 555conjugated goat anti-rabbit Ab. Nuclei were stained with DAPI. Images were captured using a Zeiss LSM510 confocal microscope. Samples were visualized under consistent contrast and brightness settings. AECs, airway epithelial cells; DAPI, 4',6-diamidino-2-phenylindole; HRP, horse radish peroxidase; Ig, Immunoglobulin; mAb, monoclonal antibody; SDS-PAGE, sodium dodecyl sulfate-polyacrylamide gel electrophoresis. 

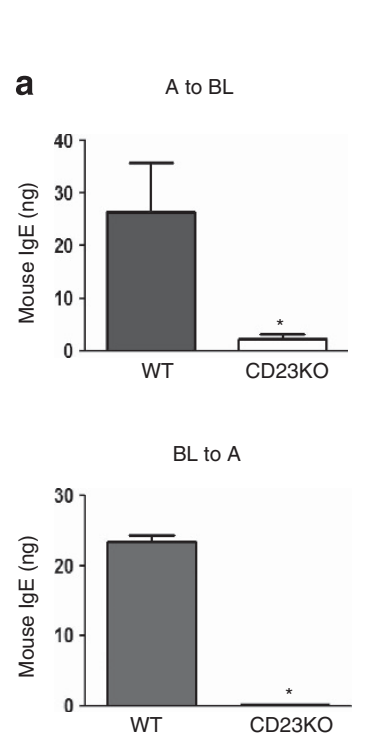
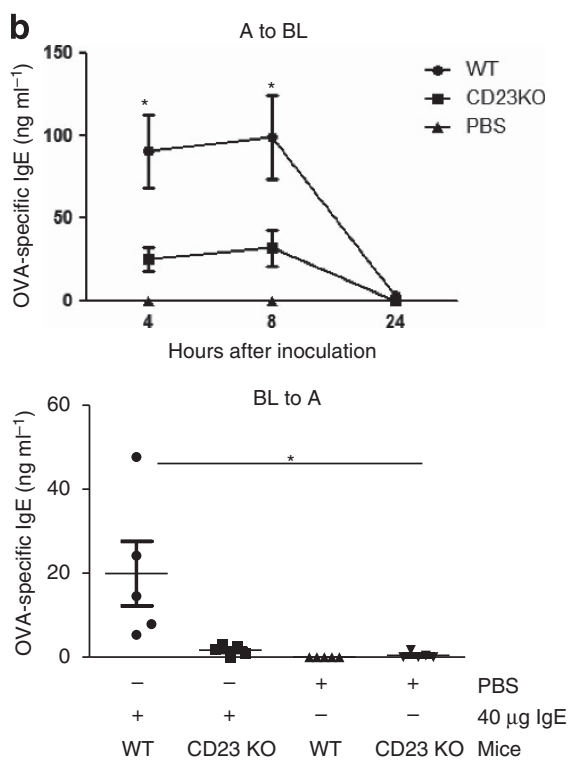

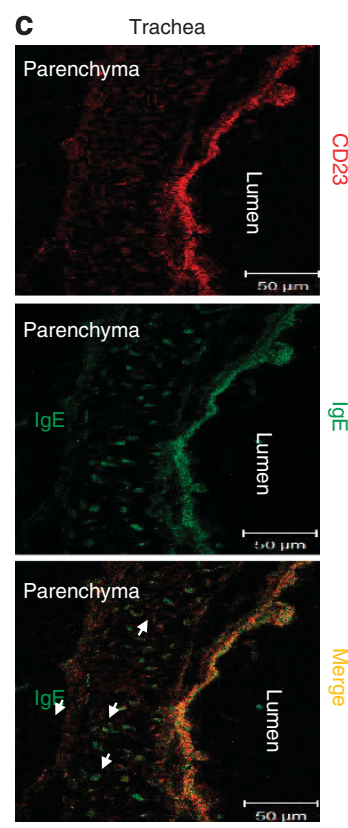

Figure 2 CD23-mediated transcytosis of IgE across mouse epithelial monolayers. (a) Transcytosis of mouse lgE in primary mouse TEC. TECs isolated from WT or CD23 KO mice were grown on transwell filters and cells were allowed to become polarized. Mouse IgE was added to the apical (top panel) or basolateral (lower panel) chambers and incubated at $37^{\circ} \mathrm{C}$ for $2 \mathrm{~h}$. The medium from opposite chamber was collected and lgE concentration was measured by ELISA. ${ }^{*} P<0.05$. (b) Airway transcytosis of mouse lgE in WT or CD23 KO mice. Top Panel: OVA-specific lgE $(40 \mu \mathrm{g})$ was i.n. inoculated into either WT or CD23 KO mice for $5 \mathrm{~min}$. Sterile PBS was used as a control. Sera were collected at indicated time points. Bottom Panel: OVA-specific IgE $(40 \mu \mathrm{g})$ or sterile PBS was i.p. inoculated into either WT or CD23 KO mice. BAL fluid was collected $8 \mathrm{~h}$ after injection. OVA-specific lgE was measured in the sera and BAL fluid by ELISA. ${ }^{*} P<0.05$. (c) Colocalization of CD23 and lgE in mouse trachea. Naive mice were anesthetized with avertin and $20 \mu \mathrm{g}$ of mouse IgE or PBS was i.n. inoculated. Mice were killed $20 \mathrm{~min}$ after treatment, and the trachea was collected and snap-frozen in OCT medium and cryosectioned at $5 \mu \mathrm{m}$. Frozen tissue sections were fixed and permeabilized with ice-cold acetone and blocked with $10 \%$ NGS. Sections were incubated with rabbit anti-CD23 Ab followed by staining with Alexa Fluor 555-conjugated goat anti-rabbit Ab (red) and FITC-conjugated goat anti-mouse IgE Ab (green). Lung epithelial cells did not stain positive with rabbit anti-IgE Ab. Images were captured using a LSM510 confocal microscope. Samples were visualized under consistent contrast and brightness settings. Arrows indicate IgE Ab transported into the parenchyma. A, apical; Ab, antibody; BAL, bronchoalveolar lavage; BL, basolateral; ELISA, enzyme-linked immunosorbent assay; FITC, fluorescein isothiocyanate; Ig, immunoglobulin; i.n., intranasally; i.p., intraperitoneally; NGS, normal goat serum; OVA, ovalbumin; PBS, phosphate-buffered saline; TEC, tracheal epithelial cells; WT, wild type.

the number of OVA challenges to a single dose. This allowed us to examine the role of CD23-mediated transcytosis in the airway inflammatory response. First, to determine whether sensitization-induced inflammation has any effect on the level of CD23 expression in epithelial cells, lysates were prepared from the lung and tracheal epithelial cells of the sensitized or naive mice. Western blot analysis of the cell lysates showed that CD23 protein was significantly upregulated in AECs of the sensitized mice compared with naive mice (Figure 4a and Supplementary Figure S7). Hence, allergic inflammation augments CD23 expression in AECs.

Previous studies have shown that $\mathrm{CD} 23 \mathrm{KO}$ mice exhibit increased allergic inflammatory responses compared with WT mice. ${ }^{18-20}$ It is possible that the deletion of CD23 in mice may result in structural changes in the lung; however, we were unable to detect any significant changes in inflammation, goblet cell hyperplasia, or peribronchial fibrosis in naive CD23 KO mice compared with naive WT mice (Supplementary Figure S8). Therefore, it is very likely that the increase in development of allergic inflammation in sensitized CD23 KO mice is directly associated with the absence of $\mathrm{CD} 23$ expression in hematopoietic cells. To compare the requirement for CD23 in hematopoietic cells and lung structural cells, especially epithelial cells, in mediating airway allergic inflammation, we created bone marrow chimeric mice. Bone marrow cells were adoptively transferred between WT and $\mathrm{CD} 23 \mathrm{KO}$ mice to generate three different chimeras: WT/CD23KO, CD23KO/ $\mathrm{WT}$, and WT/WT. In WT/CD23KO mice (where WT bone marrow was injected into irradiated $\mathrm{CD} 23 \mathrm{KO}$ recipients), the airway structural cells are $\mathrm{CD} 23$-deficient, whereas hematopoietic cells express CD23. In CD23KO/WT mice (where CD23 KO marrow was injected into irradiated WT recipients), airway structural cells express CD23, whereas hematopoietic cells are CD23-deficient. As a control, bone marrow cells from WT mice were also transferred into irradiated WT mice, generating the WT/WT chimera with both airway structural and hematopoietic cells expressing the $\mathrm{CD} 23$ receptor. The success of hematopoietic cell repopulation was verified by assessing $\mathrm{CD} 23^{+} \mathrm{B}$ cells or total B cells in spleen, bone marrow, and mononuclear cells and $\mathrm{T}$ cells in spleen and lung using flow cytometry (Supplementary Figures S9 and S10). We did not detect any significant differences in the repopulated immune cells in the lung, spleen, 

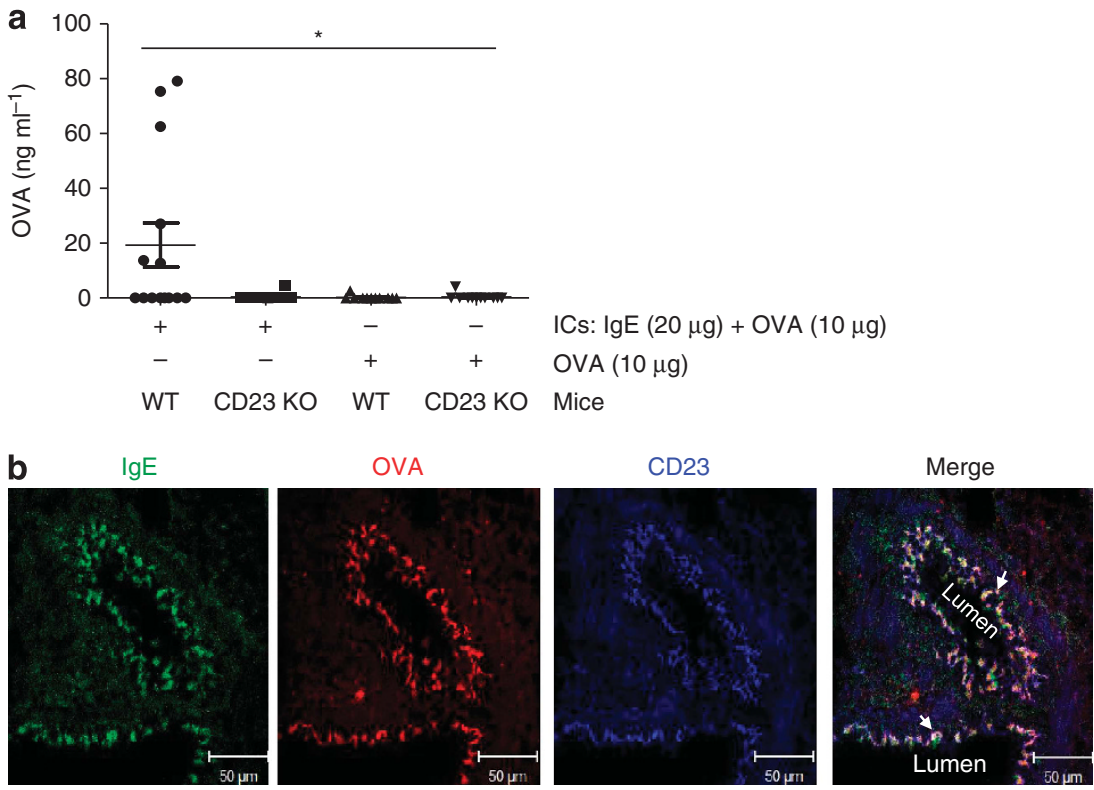

Figure 3 CD23-mediated transcytosis of OVA-IgE ICs across mouse epithelial monolayers. (a) Apical to basolateral transcytosis of ICs in naive mice. ICs were formed with $20 \mu \mathrm{g}$ OVA-specific IgE and $10 \mu \mathrm{g}$ of OVA at room temperature for $30 \mathrm{~min}$. WT or CD23 KO mice were anesthetized with avertin and ICs, $10 \mu \mathrm{g}$ OVA, or PBS was i.n. inoculated, respectively. Sera were collected $8 \mathrm{~h}$ later and OVA antigen quantitated by ELISA. * $P<0.05$. (b) Colocalization of CD23 and ICs in the lungs of naïve mice. OVA-IgE ICs or PBS were i.n. inoculated into anesthetized mice, which were killed 20 min later and lung tissue was prepared in OCT medium and cryosectioned at $5 \mu \mathrm{m}$. Frozen sections were fixed and permeabilized with ice-cold acetone and blocked with $10 \%$ NGS. Sections were incubated with rabbit anti-CD23 Ab or mouse anti-chicken OVA Ab followed by staining with Alexa fluor $633-$ conjugated goat anti-rabbit Ab, Alexa fluor 555-conjugated goat anti-mouse Ab, and FITC-conjugated goat anti-mouse IgE Ab. Nuclei were stained with DAPI and sections were imaged using a LSM510 confocal microscope. Samples were visualized under consistent contrast and brightness settings. Arrows indicate the colocalization (white). Ab, antibody; DAPI, 4',6-diamidino-2-phenylindole; FITC, fluorescein isothiocyanate; ICs, immune complexes; Ig, immunoglobulin; i.n., intranasally; KO, knockout; OVA, ovalbumin; PBS, phosphate-buffered saline; WT, wild type.

or bone marrow of chimeric mice (Supplementary Figures S9 and S10).

First, to determine the role of CD23 expressed in AECs, WT/ $\mathrm{CD} 23 \mathrm{KO}, \mathrm{CD} 23 \mathrm{KO} / \mathrm{WT}$, and $\mathrm{WT} / \mathrm{WT}$ chimeric mice were sensitized and challenged with OVA aerosol. Following the challenge, a significantly higher level of OVA antigen was detected in sera from WT/WT and $\mathrm{CD} 23 \mathrm{KO} / \mathrm{WT}$ mice compared with WT/CD23KO mice (Figure $4 \mathbf{b}$ ). Next, we assessed whether OVA-specific IgE could be detected in the BAL fluid after OVA challenge and found that both WT/WT and $\mathrm{CD} 23 \mathrm{KO} / \mathrm{WT}$ mice had significantly increased levels of OVA-specific IgE in both BAL fluid and sera compared with WT/CD23KO mice (Figure 4c). Similarly, significantly higher levels of IL-4 were detected in both sera and BAL fluid of $\mathrm{WT} / \mathrm{WT}$ and $\mathrm{CD} 23 \mathrm{KO} / \mathrm{WT}$ mice when compared with WT/ $\mathrm{CD} 23 \mathrm{KO}$ mice (Figure 4d). Although mice had equal numbers of total leukocytes in the BAL fluid, flow cytometric analysis revealed a significantly higher number of CD $45^{+} \mathrm{CD} 11 \mathrm{~b}^{\mathrm{h} / \text { int }}$ CD11c ${ }^{-}$Siglec- ${ }^{+}$eosinophils in the BAL fluid and CD45 ${ }^{+}$ $\mathrm{CD} 11 \mathrm{~b}^{\text {hi }} \mathrm{CD} 11 \mathrm{c}^{-}$Siglec- $\mathrm{F}^{+}$eosinophils in lung mononuclear cells of WT/WT mice compared with that of WT/CD23KO mice (Figures 4e1 and e2). In addition, airway function was assessed using whole-body plethysmography. After OVA challenge, WT/WT and CD23KO/WT mice developed a significantly enhanced response to methacholine compared with WT/CD23KO chimeric mice (Figure 4f). As expected, saline-treated control animals displayed a decreased response to methacholine compared with WT/WT or $\mathrm{CD} 23 \mathrm{KO} / \mathrm{WT}$ mice, with a significant difference at $\sim 50 \mathrm{mg} \mathrm{ml}^{-1}$ methacholine (Figure 4f).

Histopathological analysis of lung sections revealed remarkable structural changes in the lungs of WT/WT and CD23KO/ WT mice (Figure 5). The semi-quantitative scoring of histological lesions confirmed that WT/WT and $\mathrm{CD} 23 \mathrm{KO} /$ WT mice (mean score 3) had significantly more severe inflammation than WT/CD23KO mice (mean score 1). Lung sections of WT/WT and CD23KO/WT mice showed peribronchiolar and perivascular infiltrations of inflammatory cells (Figures 5a1 and a2) compared with WT/CD23KO (Figures 5a1 and a2) and control mice (Figure 5b). Deposition of collagen in connective tissue, detected with the MassonTrichrome staining, was found surrounding the peribronchiolar epithelial cells in lung sections from WT/WT and $\mathrm{CD} 23 \mathrm{KO} / \mathrm{WT}$ mice, but not in WT/CD23KO mice (Figure 5c). Furthermore, lung sections of WT/WT and $\mathrm{CD} 23 \mathrm{KO} / \mathrm{WT}$ mice, but not those of the WT/CD23KO mice, displayed significant increases in mucin-secreting goblet cells among the bronchial epithelial cells in response to OVA sensitization and challenge (Figure 5d1). Excessive mucus secretion from hyperplastic goblet cells is a feature of the asthmatic airway. Quantitative analysis confirmed that the numbers of goblet cells were significantly higher in WT/WT 


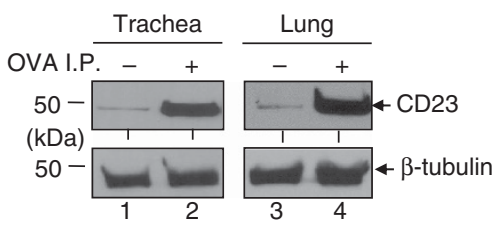

b
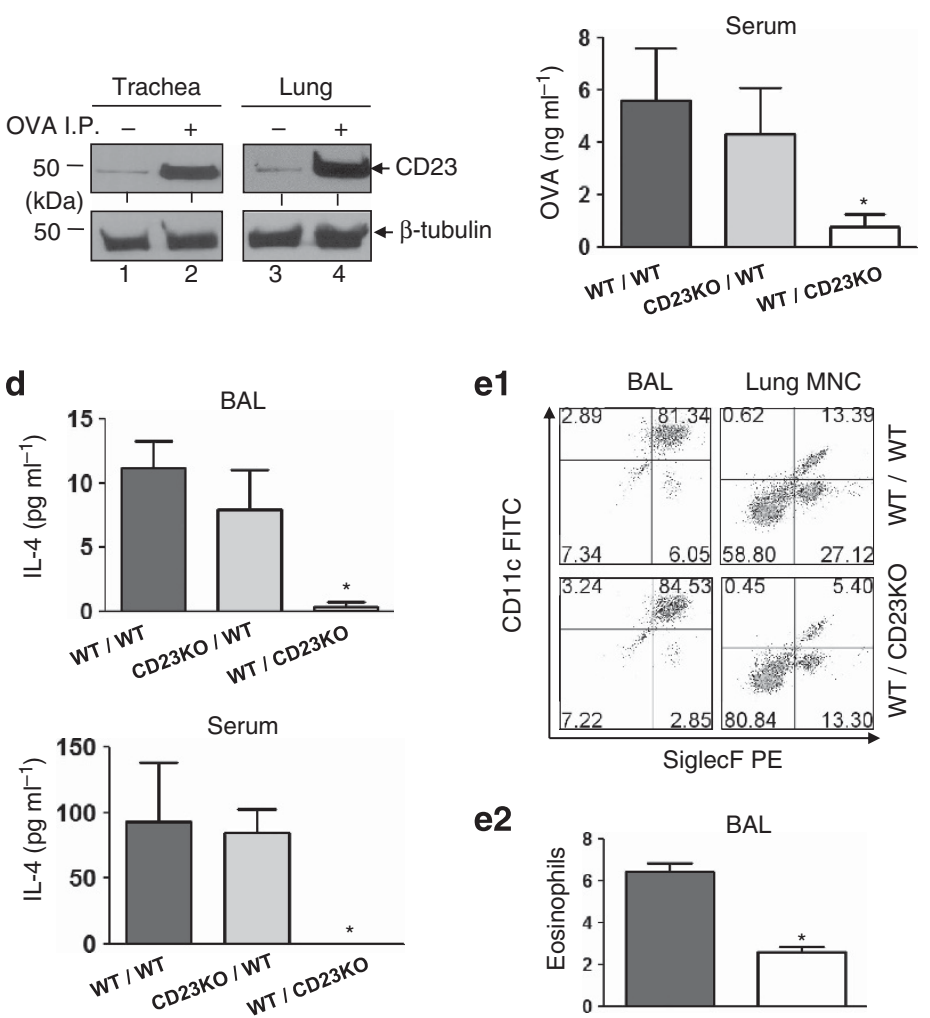

e1

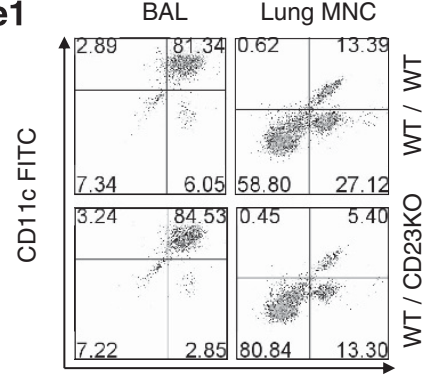

SiglecF PE

e2

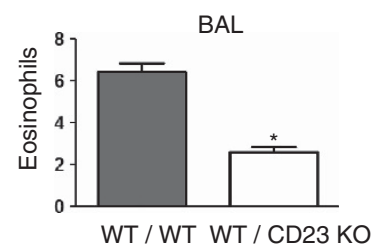



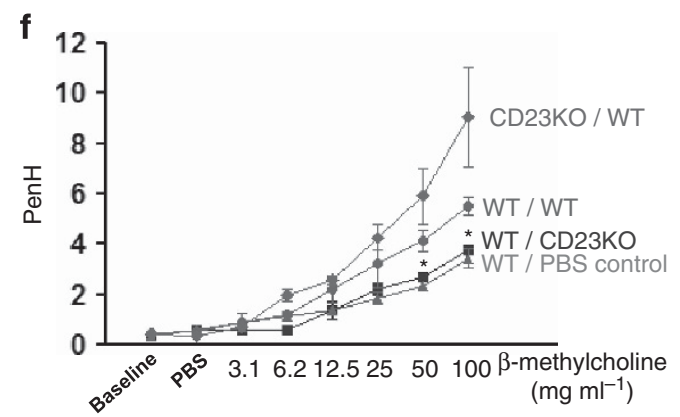

Figure 4 Epithelial CD23 facilitates airway inflammation after OVA sensitization and challenge in chimeric mice. (a) Mice were sensitized (i.p.) with OVA or left untreated. Lung and trachea epithelial cells were isolated and cell lysates $(50 \mu \mathrm{g})$ were subjected to $12 \%$ SDS-PAGE under reducing conditions. Proteins were transferred onto nitrocellulose membranes and blotted with rat-anti mouse CD23 mAb (B3B4) followed by HRP-conjugated rabbit anti-rat IgG Ab. Proteins were visualized using ECL. Arrows indicate mouse CD23 and $\beta$-tubulin. (b-d) WT/WT, CD23KO/WT, and WT/CD23KO chimeric mice were i.p. sensitized with $100 \mu \mathrm{g}$ OVA plus $4 \mathrm{mg}$ alum at day 0 and subsequently injected (i.p.) with $100 \mu \mathrm{g}$ OVA on day 7 and 14 . Mice were challenged on day 21 with nebulized $1 \%$ OVA for 30 min. $5 \mathrm{~h}$ after OVA challenge, sera were collected and OVA quantitated by ELISA. (b) Twenty-four hours after OVA challenge, BAL fluid and sera were collected and OVA-specific IgE (c) and IL-4 (d) concentrations assessed by ELISA. * $P<0.05$. (e) Flow cytometric analysis of eosinophils in BAL fluid. Chimeric mice were sensitized with OVA and received a single aerosol OVA challenge. Total leukocytes obtained from BAL fluid were gated on CD45 ${ }^{+} \mathrm{CD} 11 \mathrm{~b}^{\text {hi/int }}$ and mononuclear cells obtained from lung were gated on $\mathrm{CD} 45^{+} \mathrm{CD} 11 \mathrm{~b}^{\text {hi }}$ cells and further analyzed for CD11c and Siglec-F expression (e1). The mean percentage of eosinophils in BAL fluid from three different experiments was calculated (e2). ${ }^{*} P<0.05$. (f) Airway responsiveness to MCh in chimeric and control mice. WT/WT, CD23KO/WT, and WT/CD23KO chimeric mice were sensitized (i.p.) with OVA and received a single aerosol challenge with OVA whereas control mice were sensitized and received a single aerosol challenge with PBS. Airway resistance was measured $24 \mathrm{~h}$ after challenge. First, the baseline and resistance against PBS challenge were measured followed by generation of a dose-response curve against an increasing concentration of nebulized MCh $\left(3-100 \mathrm{mg} \mathrm{ml}^{-1}\right)$. ${ }^{*} P<0.05$. Ab, antibody; BAL, bronchoalveolar lavage; ELISA, enzymelinked immunosorbent assay; HRP, horse radish peroxidase; Ig, immunoglobulin; IL, interleukin; i.p., intraperitoneally; MCh, methacholine; OVA, ovalbumin; PBS, phosphate-buffered saline; SDS-PAGE, sodium dodecyl sulfate-polyacrylamide gel electrophoresis; WT, wild type.

and $\mathrm{CD} 23 \mathrm{KO} / \mathrm{WT}$ mice than in WT/CD23KO mice (Figure 5d2). Taken together, these data suggest that CD23 in lung structural cells, and specifically in AECs, contributes to the early stages of allergic inflammation.

\section{Targeted blocking of CD23 in the airway attenuates allergic airway inflammation}

The data described above suggest that CD23 expressed in the airway, especially in epithelial cells, is likely to play a pivotal role in the initiation and propagation of allergic airway inflammation. We reasoned that targeting CD23 in the airway could be used as a means of therapeutic intervention against asthma development. To test this hypothesis, we used a receptorblocking CD23 monoclonal $\mathrm{Ab}(\mathrm{mAb})$ that selectively binds to CD23 and prevents IgE or IC binding, consequently preventing or reducing the efficiency of the transcytosis of these molecules across the epithelial barrier. ${ }^{16}$ Using the same assay described above, we found that the mouse-specific anti-CD23 mAb, B3B4, was able to efficiently block IgE transcytosis across primary mouse tracheal epithelial cells in vitro (Figure 6a). Therefore, before OVA challenge, OVA-sensitized WT mice were i.n. treated with $75 \mu \mathrm{g}$ B3B 4 Ab or control rat IgG2a in PBS twice, once at $24 \mathrm{~h}$ before and then again $1 \mathrm{~h}$ before challenge. Five hours after the challenge, a significant amount of OVA was detected in the sera of the control IgG2a-treated mice, but not in that from B3B4-treated animals (Figure 6b). These data indicate that $\mathrm{B} 3 \mathrm{~B} 4 \mathrm{mAb}$ is able to efficiently block CD23mediated transcytosis of IgE and ICs. To determine whether B3B4 mAb-treated mice exhibited reduced inflammation, we first measured the levels of OVA-specific IgE, IL-13, and IL-5 in 


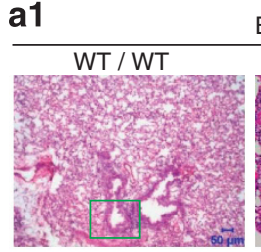

Bone marrow transfe



$\checkmark$


CD23KO / WT

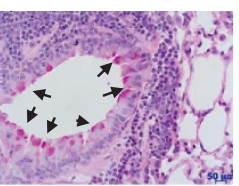

WT / CD23 KO



a2
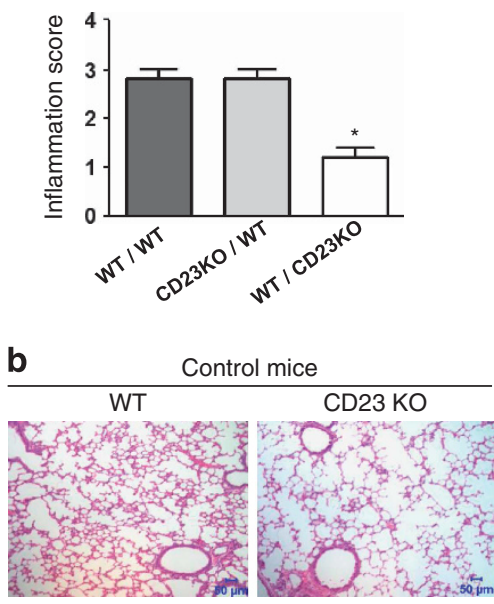

d2

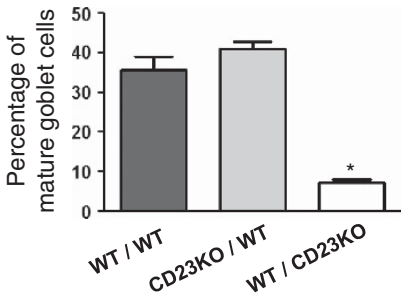

Figure 5 Effects of epithelial CD23 on pathological changes in lung. WT/WT, CD23KO/WT, and WT/CD23KO chimeric mice were sensitized with OVA and received a single aerosol OVA challenge. Lung tissues were fixed in formalin and embedded in paraffin $24 \mathrm{~h}$ after OVA challenge. (a) Lung tissue section were stained with H\&E and examined by light microscopy at the indicated magnifications. Lung sections from WT/CD23KO chimeric mice (top right) showed a significant attenuation of inflammation compared with that from WT/WT (top left) and CD23KO/WT (top middle) mice. Insets (top, green squares) are shown at a higher amplification (arrow). Pronounced alveolar and bronchiolar changes are shown in WT/WT or CD23KO/WT mice. Semiquantitation of inflammation by histological analysis (a2). ${ }^{*} P<0.05$. Lung sections from either CD23 KO or WT mice are shown in panel b. (c) Lung sections were stained using the Masson's trichrome method. WT/CD23KO chimeric mice showed significantly decreased peribronchial fibrosis (blue) in the lung compared with WT/WT or CD23KO/WT chimeric mice. Data are representative of two independent experiments. (d) Lung sections were stained with PAS. WT/CD23 KO chimeric mice showed a significant reduction in goblet-cell hyperplasia (arrows) in the lung bronchial area in comparison with that of WT/WT or CD23KO/WT chimeric mice (d1). Goblet cells were counted and the mean percentage of three different sections is indicated (d2). ${ }^{\star} P<0.05$. H\&E, Hematoxylin and Eosin; OVA, ovalbumin; PAS, Periodic Acid-Schiff; WT, wild type.

the sera or BAL fluid. Following OVA aerosol challenge, the levels of IgE, IL-13, and IL-5 were significantly lower in both BAL fluid and sera of B3B4-treated mice than in IgG2a-treated control mice (Figures $\mathbf{6 c - e}$ ). In addition, the numbers of $\mathrm{CD} 45^{+} \mathrm{CD} 11 \mathrm{~b}^{\text {hi/int }} \mathrm{CD} 11 \mathrm{c}^{-}$Siglec- $\mathrm{F}^{+}$eosinophils in the BAL of B3B4-treated mice $(3.74 \%)$ were significantly lower than those of control mice (6.4\%) (Figures 6f 1 and $\mathbf{f} 2$ ).

Histopathological analysis of lung sections revealed a remarkable difference between control and B3B4-treated mice in the pathology caused by inflammatory responses (Figure 7a1). The semi-quantitative scoring of histological lesions showed that IgG2a-treated control mice (mean score 3) had significantly more severe inflammation than B3B4-treated mice (mean score 1) (Figure 7a2). Using Masson-Trichrome staining, we found an appreciable peribronchial fibrosis (blue) in the control, but not in B3B4-treated mice (Figure 7b). We used PAS (Periodic acid-Schiff) staining to further determine the extent of mucus cell hyperplasia. Our results showed a remarkable decrease in PAS-positive cells in the bronchial epithelium of B3B4-treated mice (Figure 7c1), when compared with IgG2a-treated control mice. Also, the percentage of PASpositive cells in B3B4-treated mice was significantly lower than that in IgG2a-treated mice (Figure 7c2). Furthermore, B3B4treated animals showed a significantly decreased response to methacholine compared with control-treated mice (Figure 7d). Therefore, our results demonstrate that the in vivo treatment with CD23-blocking antibody not only interferes with the transcytosis function of epithelial CD23, but also confers effective protection against the development of allergic inflammation.

\section{DISCUSSION}

Asthma is a very heterogeneous and complex disease involving multiple pathways and cellular components in its pathogenesis. $^{21,22}$ The early response during airway allergy is strongly associated with inhaled allergens that can cross-link specific IgE molecules on the surface of immune cells, leading to their activation and release of primary inflammatory mediators by cells including $\mathrm{T}$ cells, mast cells, and basophils.. ${ }^{1,8,21}$ The latephase reaction is characterized by recruitment and activation of 

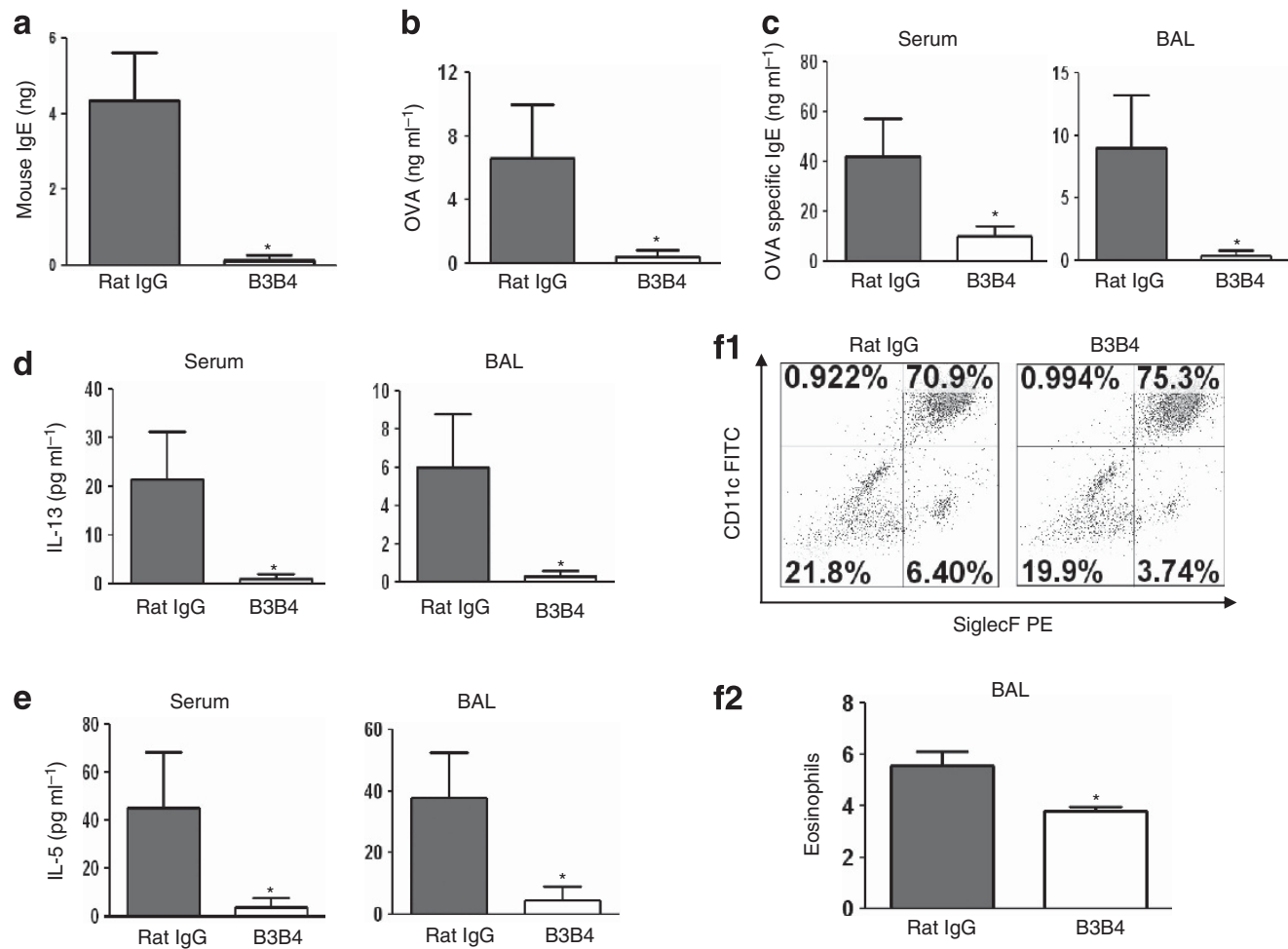

f2

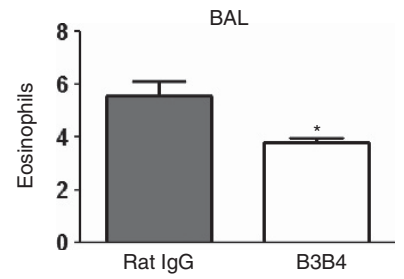

Figure 6 Effect of B3B4 Ab targeting of airway CD23 on IgE and allergen transcytosis, inflammatory cytokine production, and eosinophil infiltration. (a) B3B4 Ab blocked IgE transcytosis in primary mouse TECs. Cells were isolated from WT mice, grown on transwell filters, and allowed to polarized. Purified B3B4 Ab or rat IgG2a (50 $\mathrm{g} \mathrm{ml}^{-1}$ ) was added into the apical chamber for $45 \mathrm{~min}$ at $4{ }^{\circ} \mathrm{C}$ to allow Ab binding to apical CD23. Mouse IgE was then added to apical chambers and incubated at $37^{\circ} \mathrm{C}$ for $2 \mathrm{~h}$. Medium from the basolateral chamber was collected and IgE content measured by ELISA ${ }^{\star} P<$ 0.05. (b-f) Sensitization of mice with OVA. Before challenge, OVA-sensitized WT mice received i.n. inoculation with $75 \mu \mathrm{g} B 3 \mathrm{~B} 4 \mathrm{Ab}$ or rat IgG2a in PBS twice, once at $24 \mathrm{~h}$ before, and again $1 \mathrm{~h}$ before, challenge. Sera were collected $5 \mathrm{~h}$ after the single OVA challenge and OVA in sera was quantified by ELISA. (b) BAL fluid or sera were collected $48 \mathrm{~h}$ after OVA challenge. Concentrations of OVA-specific IgE (c), IL-13 (d), and IL-5 (e) in either BAL fluid or sera were measured by ELISA. Eosinophils were assessed by flow cytometric analysis of CD $45^{+} \mathrm{CD} 11 \mathrm{~b}^{\text {hilint }} \mathrm{CD} 11 \mathrm{c}^{-} \mathrm{Siglec}-\mathrm{F}^{+}$cells in $\mathrm{BAL}$ fluid (f1). The mean percentage of the eosinophils in the BAL fluid from three different experiments was calculated (f2). ${ }^{\star} P<0.05$. Ab, antibody; BAL, bronchoalveolar lavage; ELISA, enzyme-linked immunosorbent assay; Ig, immunoglobulin; IL, interleukin; i.n., intranasally; OVA, ovalbumin; PBS, phosphate-buffered saline; TECs, tracheal epithelial cells; WT, wild type.

leukocytes including lymphocytes, eosinophils, macrophages, and neutrophils, leading to bronchial or lung tissue infiltration. ${ }^{1,21,22}$ Additionally, the airway epithelium acts as a major barrier between the inhaled allergens and immune cells in the parenchyma. ${ }^{23,24}$ Although CD23 is known to be expressed in human AECs, ${ }^{16}$ the role of airway epithelial CD23 in the development of allergic inflammation in vivo has remained relatively undefined.

Our previous study showed that CD23 is capable of transporting $\operatorname{IgE}$ and IgE-derived ICs across polarized human AECs in vitro. ${ }^{16}$ To extend upon this observation in vivo, we demonstrated that CD23 mRNA and protein are expressed in the AECs of mice and this receptor is responsible for transporting IgE and the ICs across the airway epithelium in vivo. Furthermore, this finding was confirmed by the failure of CD23 KO mice to transport IgE or ICs across AECs, and is further supported by the co-localization of $\mathrm{CD} 23$ with i.n. inoculated IgE and OVA in mouse AECs. A previous study suggested that intestinal epithelial cells can also express Fc\&RI by immunohistochemistry; ${ }^{25}$ however, we barely detected the mouse Fc\&RI alpha chain in AECs using immunohistochemistry (Supplementary Figure S11), and therefore it is unlikely that FceRI contributes significantly to IgE transcytosis across the airway epithelium. In addition, mouse Fc $\gamma$ RII, Fc $\gamma$ RIII, and Fc $\gamma$ RIV bind to IgE or IgE ICs, but are expressed in macrophages or mast cells and not in AECs. ${ }^{26,27}$ Although IgE is clearly detected in the sera of WT mice after i.n. inoculation, the serum concentration of $\operatorname{IgE}$ may not reflect the exact amounts of IgE transported by CD23, because IgE is cytophilic and much of it presumably remains in tissues. Thus, these in vivo results together with what is known of IgE transport in human AECs in vitro confirm that CD23 mediates transepithelial transport of IgE and the ICs across the airway mucosal barrier.

The major finding of this study is that epithelial CD23 plays a critical role in initiating and facilitating allergic airway inflammation. The airway epithelium acts as a barrier preventing allergens from penetrating into the airway parenchyma; however, we have shown a role for CD23 in the transepithelial transport of IgE and ICs in vitro ${ }^{16}$ and in vivo. It is conceivable that transcytosed IgE-allergens engage immune cells leading to their activation and the release of various 
a1

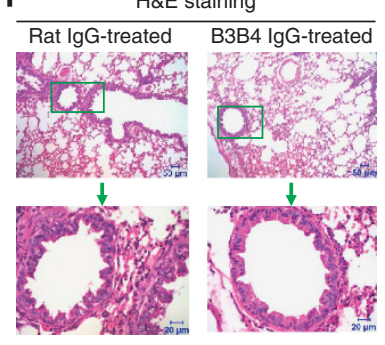

a2 b

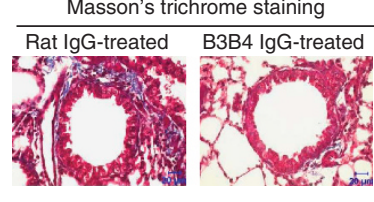

c1

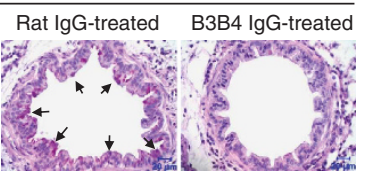

d

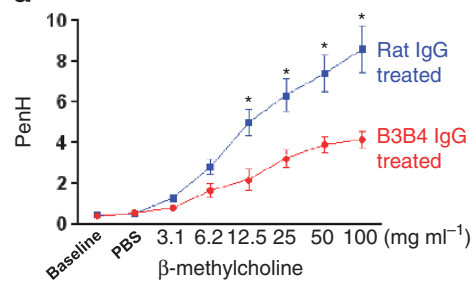

c2



Figure 7 Effect of B3B4 Ab targeting of airway CD23 on airway allergic inflammation. WT mice were sensitized with OVA and received i.n. inoculation of $75 \mu \mathrm{g} \mathrm{B3B} 4 \mathrm{Ab}$ or rat IgG2a in PBS twice, once at $24 \mathrm{~h}$ before and again $1 \mathrm{~h}$ before challenge. Subsequently, mice were challenged with OVA and $24 \mathrm{~h} \mathrm{later}$ AHR was measured, and $48 \mathrm{~h}$ later mice were killed and lung tissues were fixed in formalin and embedded in paraffin. (a) Lung sections were stained with H\&E and examined by light microscopy at the indicated magnifications. Lung sections in B3B4 Ab-treated mice showed significant attenuation of inflammation in comparison with that of control rat IgG2a-treated mice. Insets (green squares) are shown at higher amplifications. Semi-quantitative assessment of inflammation in histological sections was analyzed (a2 panel). ${ }^{\star} P<0.05$. (b) Lung tissue sections were stained using the Masson's trichrome method. B3B4 Ab-treated mice showed significantly decreased peribronchial fibrosis (blue) in the lung compared with control Ab-treated mice. (c) Lung tissue sections were stained with PAS. B3B4-treated mice had a significant reduction in goblet-cell hyperplasia in the lung bronchial area compared with that of the rat IgG2a-treated mice (c1). Goblet cells were counted and the mean percentage of three different sections is presented (c2). ${ }^{\star \star} P<0.01$. (d) Airway responsiveness to MCh in B3B4 Ab-treated mice. AHR was measured $24 \mathrm{~h}$ after a single OVA challenge. First, baseline airway resistance and resistance against PBS challenge were measured and then a dose response curve against increasing concentrations of nebulized MCh $\left(3-100 \mathrm{mg} \mathrm{ml}^{-1}\right)$ was generated. ${ }^{*} P<0.05$. Ab, antibody; AHR, airway hyper-responsiveness; BAL, bronchoalveolar lavage; H\&E, Hematoxylin and Eosin; Ig, immunoglobulin; IL, interleukin; i.n., intranasally; MCh, methacholine; OVA, ovalbumin; PAS, Periodic Acid-Schiff; PBS, phosphate-buffered saline; WT, wild type.

inflammatory and lipid mediators. In this study, the major immune cell engaged is $\mathrm{T}$ cells, which are activated via antigen presentation by dendritic cells or basophils, because the OVA/ alum sensitization and challenge mouse model used is T-celldependent. In a separate study, we are specifically testing the role of CD23-mediated IgE transport in activating mast cell degranulation through use of the mast cell/IgE-dependent mouse model. ${ }^{28,29}$

In addition, using OVA sensitization and aerosol challenge in bone-marrow chimeric mouse models, we clearly demonstrate a causal relationship between CD23 expression in airway structural cells, mainly epithelial cells and airway eosinophilia, and extensive lung damage and airway hyperactivity. There is ample evidence supporting our finding of a role for $\mathrm{CD} 23$ in this effect. First, CD23-mediated epithelial transcytosis of the ICs may protect allergens from degradation both by diverting allergens from lysosomal degradation ${ }^{30}$ and by physical binding to IgE ICs. Consistent with this, we detected intact OVA antigen in the in vitro transcytosis as well as in WT mouse sera after i.n. inoculation. ${ }^{16}$ Consequently, larger quantities of allergens gain access to immune cells, which are activated through allergen cross-linking of FcERI or antigen presentation. When administered through the airways, IgE ICs formed in vitro have been shown to be more potent than allergen alone at inducing airway inflammatory responses in sensitized mice. ${ }^{31}$ Second, in asthma patients, both CD23 expression and IgE secretion into the airway have been shown to be enhanced. $^{32,33}$ Consistent with these results, we found that mouse CD23 expression is significantly increased in the AECs of sensitized mice. Indeed, IL-4 exposure upregulates CD23 expression and enhances the transcytosis of IgE or IgE IC across a polarized human airway epithelial monolayer. ${ }^{16}$ This suggests that CD23 is likely to play similar roles in promoting human asthma by transcytosing IgE and IgE-allergen complexes across the airway epithelial barrier. Third, following passive sensitization with OVA-specific IgE antibody, WT, but not CD23 KO, mice produce significantly increased amounts of OVA-specific IgG and IgE after challenge. ${ }^{18}$ This result is likely because of CD23-mediated transport of IgE and the IgE-OVA IC across the airway epithelial barrier in WT mice. Therefore, there is abundant evidence for the involvement of CD23 expressed on structural cells in lung damage and airway hyperreactivity.

Several additional issues concerning the facilitation of airway allergic inflammation by $\mathrm{CD} 23$ should be considered. First, IgE-allergen ICs that can cross-link CD23 on AECs may initiate signaling cascades in epithelial cells contributing to the induction of pro-inflammatory cytokines and chemokines. Cytokines, in turn, cause increased CD23 expression and transcytosis of the ICs, which results in recruitment of more immune cells into the airways forming a positive feedback loop resulting in inflammation. Second, although the use of chimeric mouse models allowed us to reconstitute CD23 expression in 
hematopoietic cells in CD23KO mice, CD23 is also expressed in structural cells in the lung including in airway smooth muscle cells, although its role in these cells remains unknown. ${ }^{33}$ Airway smooth muscle hyperplasia has been observed in asthmatic airways. ${ }^{1,21,22}$ Thus, we speculate that $\mathrm{CD} 23$ may work in these cells to induce signaling following engagement by $\operatorname{IgE}$ ICs. However, because FceRI is also expressed in this cell type, ${ }^{34}$ it is possible these two receptors play redundant roles. Identification of the role of CD23 in smooth muscle cells will require further investigation. Third, in classic allergic mouse models, multiple sensitizations and challenges with allergens may compromise or damage the airway epithelial barrier. Hence, in this study, we reduced the number of challenges to a single dose and found this to be sufficient to induce appreciable allergic inflammation. However, the use of this modified model may explain the relatively low eosinophil percentages in the BAL fluid in this study. Fourth, in our study, a reciprocal chimeric mouse, $\mathrm{CD} 23 \mathrm{KO} / \mathrm{WT}$, generated by transferring $\mathrm{CD} 23 \mathrm{KO}$ bone marrow into irradiated WT recipients is used as a control. It has been suggested that $\mathrm{CD} 23 \mathrm{KO}$ mice develop enhanced allergic inflammation in the lung after sensitizations and challenges. ${ }^{18-20}$ In fact, in CD23 KO mice, B lymphocytes do synthesize more allergen-specific IgE. ${ }^{35-37}$ Our results are in agreement with these findings although the intensity of lung inflammation seems to differ. Again, this may be due to the single dose challenge we utilized. Nonetheless, when expressed in different cell types, such as in epithelial cells vs. B cells, CD23 may exert distinct effects on the development of allergic inflammation.

The capacity of CD23 to facilitate allergic inflammation in the airway epithelia may also have important implications for food allergies. In fact, expression of $\mathrm{CD} 23$ by intestinal epithelial cells of both humans and rodents has been shown. ${ }^{30,38}$ Moreover, CD23 on the intestinal epithelium is capable of transporting IgE and ICs in both in vitro and in ex vivo models. Interestingly, IL-4 also enhances transcytosis of IgE and ICs in the intestinal epithelial monolayer. Previous studies have shown that the IgE-derived ICs in an in vitro cultured, human intestinal epithelial monolayer preferentially activate the MAPK pathway causing the subsequent release of chemokines IL-8 and CCL20. ${ }^{38,39}$ This suggests that CD23 is possibly involved in signaling leading to pro-inflammatory responses. However, there is no concrete evidence supporting the concept that CD23 in the intestinal epithelium is able to directly initiate or facilitate allergic inflammation caused by food in vivo.

Intravenous infusions of $\mathrm{CD} 23$-specific $\mathrm{Ab}$ have previously been proposed as a therapeutic strategy in asthma. ${ }^{9,38}$ As CD23 expressed in the airway epithelium is likely to play a pivotal role in the initiation and development of airway allergic inflammation, we sought to test whether targeting this molecule in the airway might be useful as an early therapeutic intervention during development of asthma. Using a sensitized mouse model, we demonstrated that CD23 mAb, when administered i.n. before challenge, effectively reduces the development of lung hypersensitivity. In a previous study, we showed that human $\mathrm{CD} 23$-specific $\mathrm{Ab}$ or soluble CD23 could significantly reduce the efficiency of IgE or IC transcytosis across the human airway epithelial monolayer. ${ }^{16}$ We postulate that $\mathrm{CD} 23 \mathrm{mAb}$ selectively binds to epithelial CD23 preventing IgE or ICs from binding to $\mathrm{CD} 23$, and/or that $\mathrm{CD} 23 \mathrm{mAb}$ destabilizes the trimeric structure, which compromises CD23 affinity for IgE or enhances the sensitivity of CD23 to the cleavage by ADAM10. ${ }^{40}$ Further studies will be required in order to determine exactly which mechanisms are responsible. Nevertheless, without functional CD23, AECs are unable to capture allergens directly, thus preventing allergen transport across the epithelial barrier as well as the activation of immune cells by IgE-allergens and subsequent allergic/asthmatic symptoms.

Taken together, this study demonstrates that airway epithelial CD23 functions as a specific IgE or IC transporter in vivo. Our results allow us to propose a working model: allergen-specific IgE secreted by plasma cells is transported by CD23 to the lumen of the airway where it captures inhaled allergens by forming ICs. CD23 then mediates apical to basal transcytosis of functional IgE-allergen ICs, which are capable of activating subepithelial immune effector cells, such as mast cells, basophils, and eosinophils for degranulation and dendritic cells for antigen presentation (Supplementary Figure S12). Moreover, cytokines secreted by activated immune cells may provide feedback to the airway epithelium to increase the expression of $\mathrm{CD} 23$ and to support the influx of a new wave of inflammatory and adaptive immune cells into the airway mucosa.

\section{METHODS}

Antibodies, mice, cells, and reagents. The murine lung epithelial cell line LA4 was a kind gift from Dr Marc B. Hershenson (University of Michigan). The cells were cultured in Ham's F12K complete medium containing 15\% fetal bovine serum (FBS), 1\% L-glutamine, non-essential amino acids, $100 \mathrm{U} \mathrm{ml}^{-1}$ penicillin, and $100 \mu \mathrm{g} \mathrm{ml}^{-1}$ streptomycin. The cells were grown in a humidified atmosphere at $37^{\circ} \mathrm{C}$ containing $5 \% \mathrm{CO}_{2}$. Chicken OVA (Grade V) was purchased from Sigma Aldrich (St Louis, MO). The anti-murine CD23 antibody (Ab)-secreting hybridoma B3B4, rabbit anti-murine CD23 Ab, CD23 $\mathrm{KO}$ mouse on a Balb/c background were from Novartis (New York, $\mathrm{NY}){ }^{41}$ Six- to eight-week-old inbred female $\mathrm{Balb} / \mathrm{c}$ mice were purchased from the National Cancer Institute (Frederick, MD). All mice were bred and maintained in HEPA-filtered caging units. Animal experiments were approved by the Animal Care and Use Committee at the University of Maryland.

Mouse OVA specific IgE monoclonal antibody (mAb) was purchased from Bio X-cell (West Lebanon, NH). Rabbit anti-mouse IgE-horse radish peroxidase (HRP), normal rabbit IgG, mouse antichicken OVA mAb, and fluorescein isothiocyanate (FITC)-conjugated pan anti-cytokeratin $\mathrm{mAb}$ were purchased from Sigma Aldrich. Mouse anti- $\beta$-tubulin $\mathrm{Ab}$ was purchased from Developmental Studies Hybridoma Bank (The University of Iowa, Iowa City, IA). HRPconjugated rabbit anti-mouse IgG was obtained from Pierce (Rockford, IL). FITC-conjugated polyclonal goat anti-mouse IgE antibody was obtained from Novus Biologicals (Littleton, CO). Alexa fluor 555-conjugated goat anti-rabbit or anti-mouse IgG and Alexa fluor 633-conjugated goat anti-rabbit IgG were purchased from Invitrogen (Grand Island, NY). FITC-conjugated rat anti-mouse $\mathrm{B} 3 \mathrm{~B} 4 \mathrm{mAb}$ and rat anti-mouse $\mathrm{CD} 16 / \mathrm{CD} 32 \mathrm{Ab}$, FITC-conjugated hamster anti-mouse CD11c, FITC-conjugated hamster IgG1, Phycoerythrin-conjugated rat anti-mouse Siglec-F, Phycoerythrinconjugated rat IgG2a, Allophycocyanin (APC)-Cy7-conjugated rat 
anti-mouse CD45, and APC-Cy7-conjugated rat IgG2b were obtained from BD Pharmingen (San Diego, CA). APC-conjugated rat antimouse CD45R (B220) and FITC-conjugated rat IgG2a Ab were obtained from Caltag Laboratories (Buckingham, UK). APC-conjugated rat anti-mouse $\mathrm{CD} 11 \mathrm{~b}$ and $\mathrm{APC}$-conjugated rat IgG2b were obtained from Biolegend (San Diego, CA). Biotin-labeled mouse OVA specific IgE Ab was generated by EZ-Link Sulfo-NHS-LC-Biotin (Pierce, Rockford, IL) following the manufacturer's instruction. Recombinant murine IL-4 was from R\&D Systems (Minneapolis, $\mathrm{MN})$. Proteinase inhibitor cocktail was purchased from Calbiochem (San Diego, CA).

Reverse transcription-polymerase chain reaction (RT-PCR). Semiquantitative RT-PCR was performed on total RNA extracted from lung epithelial cell line LA4 as previously described. ${ }^{16}$ Total RNA was isolated from $2 \times 10^{6} / \mathrm{ml} \mathrm{LA} 4$ cells either mock stimulated or stimulated with murine IL-4 $\left(20 \mathrm{ng} \mathrm{ml}^{-1}\right)$ using TRIzol reagents (Invitrogen) according to the manufacturer's instruction. One-step RT-PCR kit (Qiagen, Valencia, CA) was used to perform semiquantitative RT-PCR. Negative control was performed without addition of RNA template. Primers used for amplification of murine $\mathrm{CD} 23 a, \mathrm{CD} 23 b$, and murine $\mathrm{CD} 23 \mathrm{~b} \Delta 5$ lacking exon $5^{17}$ were described previously. Primers used for the amplification of gylceraldehyde-3-phosphate dehydrogenase (GAPDH) were $5^{\prime}$-ACCC AGAAGACTGTGGATGG- $3^{\prime}$ and $5^{\prime}$-CACATTGGGGGTAGGAAC AC- $3^{\prime}$. Amplification of CD23 mRNA and GAPDH was performed with $450 \mathrm{ng}$ of total RNA in $20-\mu \mathrm{l}$ volume. One step RT-PCR amplification consisted of reverse transcription at $50{ }^{\circ} \mathrm{C}$ for $30 \mathrm{~min}$, initial PCR activation at $95^{\circ} \mathrm{C}$ for $15 \mathrm{~min}$, followed by PCR cycle of denaturation at $94^{\circ} \mathrm{C}$ for $1 \mathrm{~min}$, annealing at $60^{\circ} \mathrm{C}$ for $1 \mathrm{~min}$, extension at $72{ }^{\circ} \mathrm{C}$ for $2 \mathrm{~min}$ for 40 cycles, and a final extension at $72^{\circ} \mathrm{C}$ for $10 \mathrm{~min}$. Annealing temperature for GAPDH was $55^{\circ} \mathrm{C}$ for $1 \mathrm{~min}$ and the rest of the amplification conditions was same. RT-PCR products were analyzed by resolving on $1.5 \%$ agarose gel and DNA visualized by ethidium bromide staining. Semi-quantitative analysis of CD23 band intensities of RT-PCR products normalized to GAPDH values were analyzed by densitometry using Adobe Photoshop.

Genotyping of CD23 KO mice. Genotyping of the CD23 KO mice was performed with genomic DNA isolated from mouse tail using Puregene DNA isolation kit (Qiagen) following the manufacturer's protocol. Primers used for genotyping were previously described. ${ }^{41}$ PCR amplification cycle consisted of initial PCR activation at $94{ }^{\circ} \mathrm{C}$ for $3 \mathrm{~min}$, followed by PCR cycle of denaturation at $94{ }^{\circ} \mathrm{C}$ for $30 \mathrm{~s}$, annealing at $63^{\circ} \mathrm{C}$ for $1 \mathrm{~min}$, extension at $72^{\circ} \mathrm{C}$ for $2 \mathrm{~min}$ for $35 \mathrm{cycles}$, and final extension at $72{ }^{\circ} \mathrm{C}$ for $10 \mathrm{~min}$. PCR products were analyzed by resolving on $1.5 \%$ agarose gel and DNA bands were visualized by ethidium bromide staining.

\section{Sodium dodecyl sulfate-polyacrylamide gel electrophoresis and western blotting. Sodium dodecyl sulfate-polyacrylamide gel elec- trophoresis and western blot were performed as described pre- viously. ${ }^{16}$ Protein concentrations of cell lysates were determined by Bradford method. The cell lysates were resolved on $12 \%$ sodium dodecyl sulfate-polyacrylamide gel electrophoresis under reducing conditions. Proteins were transferred onto a nitrocellulose membrane (Schleicher \& Schuell, Keene, NH) and the membrane was blocked with 5\% skim milk in PBS. The membranes were probed separately with rat anti-mouse $\mathrm{CD} 23 \mathrm{mAb} \mathrm{B} 3 \mathrm{~B} 4$ or murine anti- $\beta$-tubulin $\mathrm{Ab}$ for $1 \mathrm{~h}$ at room temperature or overnight at $4{ }^{\circ} \mathrm{C}$ and then incubated with HRP-conjugated rabbit anti-rat Ab or HRP-conjugated rabbit anti- mouse $\mathrm{Ab}$. All blocking, incubation, and washing procedures were performed in PBST solution (PBS and $0.05 \%$ Tween 20). Proteins were visualized using ECL method (Pierce).}

Preparation of primary bronchoalveolar, tracheal epithelial, and lung mononuclear cells. The bronchoalveolar epithelial cells were isolated as previously described. ${ }^{42}$ The tracheal epithelial cells were isolated by following the procedures as described previously. ${ }^{43}$ The lung mononuclear cells were isolated by following the protocol as described previously. ${ }^{44}$ Briefly, the bronchoalveolar, tracheal epithelial cells and lung mononuclear cells were isolated by enzymatic digestion of lung with dispase (2.4 units/ml in Dulbecco's Modified Eagle's medium), trachea with pronase $\left(1.5 \mathrm{mg} \mathrm{ml}^{-1}\right.$ in Ham's F-12 pen-strep) and lung with collagenase type $4\left(1.25 \mathrm{mg} \mathrm{ml}^{-1}\right.$ in RPMI 1640 medium $)$ and the remaining procedures were performed as described previously. ${ }^{42-44}$

Immunohistochemistry. Immunohistochemistry was performed as previously described. ${ }^{15}$ Mouse lung and trachea were inflated and embedded with Tissue-Tek OCT medium purchased from Sakura (Torrance, CA) and cryosectioned at $5 \mu \mathrm{m}$. The tissue sections were fixed and permeabilized with ice-cold acetone for $20 \mathrm{~min}$ and blocked with $10 \%$ normal goat serum (NGS) for $1 \mathrm{~h}$ at room temperature. Tissue sections were incubated with affinity-purified rabbit antimouse CD23 Ab, FITC-conjugated pan-cytokeratin Ab, FITC-conjugated goat-anti mouse IgE $\mathrm{Ab}$, or mouse anti-chicken OVA $\mathrm{Ab}$ in a humidified chamber overnight at $4{ }^{\circ} \mathrm{C}$ followed by Alexa fluor 555 conjugated goat anti-mouse Ab or Alexa fluor 555- or 633-conjugated goat anti-rabbit $\mathrm{Ab}$. All incubations were performed with $3 \%$ NGS and finally nuclei were counterstained with 4,,6-diamidino-2-phenylindole $\left(0.5 \mathrm{~g} \mathrm{ml}^{-1}\right.$, Molecular Probes, Grand Island, NY) in PBS. Negative controls were performed by incubating the isotype-matched mouse or normal rabbit IgG as primary $\mathrm{Ab}$. Cover slips were mounted on the tissue sections with Prolong antifade reagent (Molecular probes, Invitrogen) and visualized and images were taken using Zeiss LSM510 laser scanning confocal microscope (Zeiss Microimaging, Thornwood, NY). Images were processed by Zen 2007 software and Adobe Photoshop.

In vitro and in vivo transcytosis. In vitro transcytosis was performed as previously described with modifications. ${ }^{16}$ Tracheal epithelial cells from WT or CD23 KO mice were grown onto $0.4-\mu \mathrm{m}$-pore size Transwell inserts (BD Biosciences, San Jose, CA) to form a monolayer exhibiting transepithelial electrical resistances $\left(1,500 \Omega \mathrm{cm}^{-2}\right)$. Transepithelial resistance was measured using a tissue-resistance measurement equipped with planar electrodes (World Precision Instruments, Sarasota, FL). Monolayers were equilibrated in serum-free Dulbecco's Modified Eagle's medium. Mouse IgE was added to either the apical $\left(50 \mu \mathrm{g} 250 \mu \mathrm{l}^{-1}\right)$ or the basolateral $\left(50 \mu \mathrm{g} 500 \mu \mathrm{l}^{-1}\right)$ side. They were incubated at $37^{\circ} \mathrm{C}$ for $2 \mathrm{~h}$. For negative control, monolayers were also incubated at $4{ }^{\circ} \mathrm{C}$ for $1 \mathrm{~h}$ before transcytosis. The media from the opposite chambers were collected and IgE was measured by ELISA.

In vivo transcytosis was performed with a set of $\mathrm{WT}$ and $\mathrm{CD} 23 \mathrm{KO}$ mice. Mouse OVA specific IgE $\left(50 \mu \mathrm{g} 40 \mu \mathrm{l}^{-1}\right)$ in PBS was given either i.n. or i.p. Four, 8 , or $24 \mathrm{~h}$ later, serum or BAL fluids were sampled, respectively. ICs formed with mouse OVA specific IgE $(20 \mu \mathrm{g})$ and chicken OVA $\left(10 \mu \mathrm{g} 40 \mu \mathrm{l}^{-1}\right)$ in PBS for $30 \mathrm{~min}$ at room temperature. Mice were i.n. inoculated with ICs or chicken OVA antigen alone $\left(10 \mu \mathrm{g} 40 \mu \mathrm{l}^{-1}\right)$ in PBS; $8 \mathrm{~h}$ later, sera were sampled. The concentration of OVA-specific IgE and OVA were determined by ELISA.

Enzyme-linked immunosorbent assay (ELISA). The OVA-specific IgE and OVA concentrations were measured with ELISA. ELISA plates (Nunc) were coated overnight at $4{ }^{\circ} \mathrm{C}$ with rabbit anti-chicken OVA Ab $\left(10 \mu \mathrm{g} \mathrm{ml}^{-1}\right)$ for detecting OVA or with chicken OVA $\left(10 \mu \mathrm{g} \mathrm{ml}^{-1}\right)$ for detecting OVA-specific IgE Ab. Plates were then washed three times with PBST (0.05\% tween-20 in PBS) and blocked with $10 \%$ FBS in PBS for $1 \mathrm{~h}$ at room temperature. IgE or OVA diluted in $10 \%$ FBS with PBS was used as a standard. Biotinylated anti-mouse $\operatorname{IgE} \mathrm{Ab}$ (1:500, OptEIA mouse IgE ELISA kit, BD) and HRPconjugated streptavidin (1:250, OptEIA mouse IgE ELISA kit, BD) were used for detection of mouse IgE Ab. For detection of chicken OVA, biotinylated mouse OVA-specific IgE (1:10,000) and HRPconjugated streptavidin (1:250, BD) were used. Total IgE was determined by using OptEIA mouse IgE ELISA kit following the manufacturer's protocol (BD). The readout was carried out using 
Victor III microplate reader (Perkin Elmer, Waltham, MA). The concentrations of mouse IL-4 and IL-5 (ELISA kit from BD Pharmingen) and IL-13 (ELISA kit from eBioscience, San Diego, $\mathrm{CA}$ ) were measured using the manufacturer's protocols.

Generation of bone-marrow chimeric mouse. Six- to 8-week-old WT or $\mathrm{CD} 23 \mathrm{KO}$ mice on Balb/c background were irradiated with $8 \mathrm{~Gy}$ (USDA ARS, Beltsville, MD) and repopulated intravenously with $5 \times 10^{6}$ bone marrow cells from WT or CD23 KO mouse. The irradiated recipient mice were maintained on antibiotic-water for 2 weeks. Repopulated cells in the recipient mice, WT/WT (irradiated WT mice infused with WT cells), WT/CD23KO (irradiated CD23KO mice infused with WT cells), and CD23KO/WT (irradiated WT mice infused with CD23KO cells) were determined 4 or 8 weeks later by analyzing CD23 expression in the B cells, total T cells in spleen, bone marrow, and lung mononuclear cells by flow cytometry.

Flow cytometry. Flow cytometry was used for analyzing surface expression of CD23 on the splenic B and T cells isolated from WT, CD23 $\mathrm{KO}$, and chimeric mice. The CD11b ${ }^{+/-}, \mathrm{CD} 45, \mathrm{CD} 11 \mathrm{c}$, and Siglec- $\mathrm{F}^{+/-}$ cells in the BAL or lung mononuclear cells were also analyzed. In brief, $1 \times 10^{6}$ spleen cells, $1 \times 10^{6}$ lung mononuclear cells, or $1 \times 10^{5} \mathrm{BAL}$ cells (pooled from five mice) were washed with FACS washing buffer (2\% FBS in PBS) and followed by blocking mouse Fc binding with CD16-CD32 mAb (BD) on ice for $30 \mathrm{~min}$. The cell suspensions were, respectively, incubated with murine FITC-conjugated anti-CD23 B3B4 mAb, FITC-conjugated rat IgG2a, APC-Cy7-conjugated anti-B220 Ab, APC-Cy7-conjugated rat IgG2a Ab, FITC-conjugated hamster anti-mouse CD11c, Phycoerythrinconjugated rat anti-mouse Siglec-F, FITC-conjugated hamster IgG1, Phycoerythrin-conjugated rat IgG2a, APC-conjugated rat anti-mouse $\mathrm{CD} 11 \mathrm{~b}, \mathrm{APC}$-conjugated rat IgG2b, APC-Cy7-conjugated rat anti-mouse $\mathrm{CD} 45$, and APC-Cy7-conjugated rat IgG2b for $30 \mathrm{~min}$ at $4{ }^{\circ} \mathrm{C}$, then washed and analyzed using a FACSAria II (BD) and the software FlowJo.

Mouse sensitization and challenge. Groups of WT, WT/WT, $\mathrm{CD} 23 \mathrm{KO} / \mathrm{WT}$, and WT/CD23KO mice were sensitized with OVA by mixing with alum and given intraperitoneally (i.p.). Sterile PBS was used as a placebo control. Mice were sensitized by i.p. injection of $100 \mu \mathrm{g}$ OVA emulsified in $4 \mathrm{mg}$ aluminum hydroxide (AlumInject; Pierce Chemical, Rockford, IL) in a total volume of $100 \mu \mathrm{l}$ on day 1 , followed by $100 \mu \mathrm{g}$ OVA on day 7 and 14 . Mice were then challenged via the airways with nebulized OVA (1\% in PBS) or PBS for 30 min on day 21. On day 22, AHR was measured. On day 22 or 23 , the mice were killed to collect BAL fluid, serum, and lung tissue for histopathology staining. For B3B4 antibody blocking experiment, the OVA-sensitized WT mice received $75 \mu \mathrm{g}$ of $\mathrm{B} 3 \mathrm{~B} 4$ or rat IgG2a i.n. after light anesthetization with avertin (i.p.) on day 20 and day 21 before challenge. One hour later after second treatment, the Ab treated mice were challenged. On day 22, AHR was measured and on day 23 , the mice were killed to collect BAL fluid, serum, and lung tissue for histopathology staining. BAL fluid was subjected to cytospin, staining with modified Wright-Giemsa stain (Sigma), and differential counting of cells.

Measurement of AHR. AHR was measured $24 \mathrm{~h}$ after OVA challenge in conscious, unrestrained, ventilated mice by whole-body plethysmograph (EMKA Technologies, Paris, France) as previously described. ${ }^{45}$ In comparison with the invasive method, we elect to use the noninvasive method to measure the dynamical changes in inflammatory responses. Briefly, mice were first exposed to nebulized physiologic saline for $3 \mathrm{~min}$ and then exposed to increasing concentrations of nebulized $\beta$-methacholine (Sigma) $\left(3-100 \mathrm{mg} \mathrm{ml}^{-1}\right.$ ) by use of an ultrasonic nebulizer. Measurements were obtained for 3 min after the completion of each nebulization. Penh values measured during this period were averaged and expressed as absolute Penh values.

Histopathology. Mice were euthanized and lungs were fixed immediately in $10 \%$ buffered formalin. The fixed tissues were embedded in paraffin, sectioned and stained with Hematoxylin and
Eosin. The stained sections were examined under light microscope (Carl Zeiss, Thornwood, NY) and pathological lesions were recorded. The lesions of the lungs were scored from 0 to 3 , on the basis of severity of cellular infiltration and structural alterations in pulmonary airways as follows; no lesions (score 0), mild peri-bronchiolar inflammation (score 1), moderate peri-bronchiolar inflammation and bronchiolar wall thickening (score 2), and severe peri-bronchiolar inflammation and bronchiolar wall thickening (score 3 ). The semi-quantitative measurements of lung inflammations was based on the scores above. The adjacent sections were processed for PAS staining for demonstration of mucus-secreting goblet cells and Masson-Trichrome staining for demonstration of collagen deposition in the bronchiolar wall.

Statistics. The statistical difference between groups was tested by Student $t$ test. A $P$ value of less than 0.05 was considered significant. Data are expressed as mean \pm SD.

SUPPLEMENTARY MATERIAL is linked to the online version of the paper at http://www.nature.com/mi

\section{ACKNOWLEDGMENTS}

We are grateful to Dr Marc B. Hershenson for supplying us with LA4 cell line. We thank Dr Richard S. Blumberg and Dr Steve Brody for helpful suggestions. We also acknowledge the helpful discussions with Drs David Mosser, Volker Briken, and Siba Samal. We are most grateful for the technical help from Dr Yunsheng Wang, Dr Douglas A. Powell, Dr Liming Wu, Dr Weizhong Li, Ms Susan Park-Ochsner, Ms Lauren Gilliam, and Ms Dawn Jackson. This work was in part supported by National Institutes of Health grant Al101752 (X.Z.), fellowships from the American Association of Immunologists (A.A.I.) Careers in Immunology Fellowship (S.P. and X.Z.) and Chinese Scholar Council (A.M. and J.T.).

\section{AUTHOR CONTRIBUTIONS}

S.P., A.D.K., and X.Z. designed experiments. X.L., S.P., J.T., A.M., M.J., W.T., and W.S. conducted experiments. D.H.C. provided the critical reagents. S.P., MJ, WT, WS, A.D.K., D.H.C., and X.Z. analyzed data, wrote the paper, and provided editorial suggestions.

\section{DISCLOSURE}

S.P., and X.Z. filed a patent disclosure to the University of Maryland, College Park, MD, USA.

c) 2015 Society for Mucosal Immunology

\section{REFERENCES}

1. Galli, S.J., Tsai, M. \& Piliponsky, A.M. The development of allergic inflammation. Nature 454, 445-454 (2008).

2. Licona-Limón, P., Kim, L.K., Palm, N.W. \& Flavell, R.A. TH2, allergy and group 2 innate lymphoid cells. Nat. Immunol. 14, 536-542 (2013).

3. Crimi, E., Scordamaglia, A., Crimi, P., Zupo, S. \& Barocci, S. Total and specific lgE inserum, bronchial lavage and bronchoalveolar lavage of asthmatic patients. Allergy 38, 553-559 (1983).

4. Balzar, S., Strand, M., Rhodes, D. \& Wenzel, S.E. Local IgE expression pattern in lung: relation to systemic IgE and asthma phenotypes. J. Allergy Clin. Immunol. 119, 855-862 (2007).

5. Fiset, P.O., Cameron, L. \& Hamid, Q. Local isotype switching to lgE in airway mucosa. J. Allergy Clin. Immunol. 116, 233-236 (2005).

6. Takhar, P. et al. Allergen drives class switching to lgE in the nasal mucosa in allergic rhinitis. J. Immunol. 174, 5024-5032 (2005).

7. Dakhama, A. et al. The role of virus specific immunoglobulin $E$ in airway hyperresponsiveness. Am. J. Respir. Crit. Care Med. 170, 952959 (2004).

8. Oshiba, A. et al. Modulation of antigen-induced B and T cell responses by antigen specific IgE antibodies. J. Immunol. 159, 4056-4063 (1997).

9. Conrad, D.H., Ford, J.W., Sturgill, J.L. \& Gibb, D.R. CD23: an overlooked regulator of allergic disease. Curr. Allergy Asthma Rep. 7, 331-337 (2007). 
10. Acharya, M. et al. CD23/FceRIl: molecular multi-tasking. Clin. Exp. Immunol. 162, 12-23 (2010).

11. Beavil, A.J., Edmeades, R.L., Gould, H.J. \& Sutton, B.J. Alphahelical coiled-coil stalks in the low-affinity receptor for IgE ( $F c$ epsilon RII/CD23) and related C-type lectins. Proc. Natl. Acad. Sci. U S A 89, 753757 (1992)

12. Dierks, S.E. et al. The oligomeric nature of the murine Fc epsilon RII/CD23. Implications for function. J. Immunol. 150, 2372-2382 (1993).

13. Yu, P., Kosco-Vilbois, M., Richards, M., Köhler, G. \& Lamers, M.C. Negative feedback regulation of IgE synthesis by murine CD23. Nature 369, 753-756 (1994).

14. Dhaliwal, B. et al. Crystal structure of IgE bound to its B-cell receptor CD23 reveals a mechanism of reciprocal allosteric inhibition with high affinity receptor FceRI. Proc. Natl. Acad. Sci. U S A. 109, 12686-12691 (2012).

15. Kim, K.J. \& Malik, A.B. Protein transport across the lung epithelial barrier. Am. J. Physiol. Lung Cell Mol. Physiol. 284, L247-L259 (2003).

16. Palaniyandi, S., Tomei, E., Li, Z., Conrad, D.H. \& Zhu, X. CD23-dependent transcytosis of IgE and immune complex across the polarized human respiratory epithelial cells. J. Immunol. 186, 3484-3496 (2011).

17. Yu, L.C. et al. Intestinal epithelial CD23 mediates enhanced antigen transport in allergy: evidence for novel splice forms. Am. J. Physiol. Gastrointest. Liver Physiol. 285, G223-G234 (2003).

18. Haczku, A. et al. CD23 deficient mice develop allergic airway hyperresponsiveness following sensitization with ovalbumin. Am. J. Respir. Crit. Care Med. 156, 1945-1955 (1997).

19. Cernadas, M. et al. CD23 and allergic pulmonary inflammation: potential role as an inhibitor. Am. J. Respir. Cell Mol. Biol. 20, 1-8 (1999).

20. Riffo-Vasquez, Y. et al. The role of CD23 on allergen-induced IgE levels, pulmonary eosinophilia and bronchial hyperresponsiveness in mice. Clin. Exp. Allergy. 30, 728-738 (2000).

21. Gould, H.J. \& Sutton, B.J. IgE in allergy and asthma today. Nat. Rev. Immunol. 8, 205-217 (2008).

22. Galli, S.J. \& Tsai, M. IgE and mast cells in allergic disease. Nat. Med 18, 693-704 (2012).

23. Holgate, S.T. The sentinel role of the airway epithelium in asthma pathogenesis. Immunol. Rev. 242, 205-219 (2011).

24. Schleimer, R.P., Kato, A., Kern, R., Kuperman, D. \& Avila, P.C. Epithelium: at the interface of innate and adaptive immune responses. J. Allergy Clin. Immunol. 120, 1279-1284 (2007).

25. Untersmayr, E. et al. The high affinity IgE receptor Fc epsilonRI is expressed by human intestinal epithelial cells. PLoS One 5, e9023 (2010).

26. Takizawa, F., Adamczewski, M. \& Kinet, J.P. Identification of the low affinity receptor for immunoglobulin $E$ on mouse mast cells and macrophages as Fc gamma RII and Fc gamma RIII. J. Exp. Med. 176, 469-475 (1992).

27. Hirano, M. et al. IgEb immune complexes activate macrophages through FcgammaRIV binding. Nat. Immunol. 8, 762-771 (2007).

28. Williams, C.M. \& Galli, S.J. Mast cells can amplify airway reactivity and features of chronic inflammation in an asthma model in mice. J. Exp. Med. 192, 455-462 (2000).

29. Mathews, J.A. et al. A potential new target for asthma therapy: a disintegrin and metalloprotease 10 (ADAM10) involvement in murine experimental asthma. Allergy 66, 1193-1200 (2011).
30. Yang, P.C., Berin, M.C., Yu, L.C., Conrad, D.H. \& Perdue, M.H. Enhanced intestinal transepithelial antigen transport in allergic rats is mediated by IgE and CD23 (FcepsilonRII). J. Clin. Invest. 106, 879-886 (2000).

31. Zuberi, R.I., Apgar, J.R., Chen, S.S. \& Liu, F.T. Role for IgE in airway secretions: IgE immune complexes are more potent inducers than antigen alone of airway inflammation in a murine model. J. Immunol. 164, 2667-2673 (2000).

32. Aberle, N., Gagro, A., Rabatić, S., Reiner-Banovac, Z. \& Dekaris, D. Expression of CD23 antigen and its ligands in children with intrinsic and extrinsic asthma. Allergy 52, 1238-1242 (1997).

33. Hakonarson, H.C., Carter, C., Kim, C. \& Grunstein, M.M. Altered expression and action of the low-affinity lgE receptor FCERII (CD23) in asthmatic airway smooth muscle. J. Allergy Clin. Immunol. 104, 575-584 (1999).

34. Gounni, A.S. et al. Human airway smooth muscle cells express the high affinity receptor for lgE (Fc epsilon RI): a critical role of $\mathrm{Fc}$ epsilon $\mathrm{Rl}$ in human airway smooth muscle cell function. J. Immunol. 175, 2613-2621 (2005).

35. Payet, M.E., Woodward, E.C. \& Conrad, D.H. Humoral response suppression observed with CD23 transgenics. J. Immunol. 163, 217-223 (1999).

36. Hibbert, R.G. et al. The structure of human CD23 and its interactions with IgE and CD21. J. Exp. Med. 202, 751-760 (2005).

37. Haczku, A. et al. CD23 exhibits negative regulatory effects on allergic sensitization and airway hyperresponsiveness. Am. J. Respir. Crit. Care Med. 161, 952-960 (2000).

38. $\mathrm{Li}, \mathrm{H}$. et al. Allergen-lgE complexes trigger CD23-dependent CCL20 release from human intestinal epithelial cells. Gastroenterology 133, 1905-1915 (2007).

39. Tu, Y. \& Perdue, M.H. CD23-mediated transport of lgE/immune complexes across human intestinal epithelium: role of p38 MAPK. Am. J. Physiol. Gastrointest. Liver Physiol. 291, G532-G538 (2006).

40. Weskamp, G. et al. ADAM10 is a principal 'sheddase' of the low-affinity immunoglobulin E receptor CD23. Nat. Immunol. 7, 1293-1298 (2006).

41. Stief, A. et al. Mice deficient in CD23 reveal its modulatory role in IgE production but no role in T and B cell development. J. Immunol. 152, 3378-3390 (1994).

42. Warshamana, G.S., Corti, M. \& Brody, A.R. TNF- $\alpha$, PDGF, and TGF- $\beta 1$ expression by primary mouse bronchiolar-alveolar epithelial and mesenchymal cells: TNF- $\alpha$ induces TGF- $\beta 1$. Exp. Mol. Pathol. 71, 13-33 (2001).

43. You, Y., Richer, E.J., Huang, T. \& Brody, S.L. Growth and differentiation of mouse tracheal epithelial cells: selection of a proliferative population. Am. J. Physiol. Lung Cell Mol. Physiol 283, L1315-L1321 (2002).

44. Jones, T.G. et al. Antigen-induced increases in pulmonary mast cell progenitor numbers depend on IL9 and CD1d-restricted NKT cells. J. Immunol. 183, 5251-5260 (2009).

45. Hamelmann, E. et al. Noninvasive measurement of airway responsiveness in allergic mice using barometric plethysmography. Am. J. Respir. Crit. Care Med. 156, 766-775 (1997). 